\title{
Tasawuf Transformatif di Indonesia
}

\author{
Nurul Anam, Sayyidah Syaikhotin, Hasyim Asy'ari \\ Institut Agama Islam Al-Qodiri Jember \\ nurul.anam86@gmail.com
}

\begin{abstract}
;
In Islam there is an element of Sufism which is a very significant part of the existence of transformative Islam. From this transformative Islam the term transformative Sufism emerged. The transformative Sufism process will begin and center on marifah and tauhid. In the context of transformative Sufism, understanding of haqiqah starting from all the realities that bring people to the level of maahrifah must be realized / contextualized into the social-community context. Transformative Sufism is commonly found in Sufism assemblies in Indonesia, one of which is in the Maiyahan Mbah Nun Majlis (Ainun Nadjib) in Jogjakarta Province and Majlis Zikir Manakib Sheikh Abdul Qodir Al-Jailani KH. Ahmad Muzakki Syah in Jember Regency. These majlis events are interspersed with the planting of values and the development of Islamic teachings and nationalities, so that finally the event in this assembly can be beneficial for changes for the community, especially the istiqamah pilgrims who attend this majlis. Both of these assemblies are based on Ahlussunnah Wal Jamaah Nahdlatul Ulama (NU). As is known, through the direction and guidance of KH. Hasyim Asy'ari and strengthened again by KH. Ahmad Siddiq and $\mathrm{KH}$. Abdurrahman Wahid, NU institutionally acknowledged and established the Pancasila values as the final basis for the Indonesian nation.
\end{abstract}

Keywords: Transformative Sufism, Indonesia

\begin{abstract}
Abstrak;
Di dalam Islam terdapat unsur tasawuf yang menjadi bagian yang sangat signifikan bagi keberadaan Islam transformatif. Dari Islam tranformatif ini muncul istilah tasawuf tranformatif. Proses tasawuf transformatif akan bermula dan berpusat pada ma'rifah dan taubid. Dalam konteks tasawuf tranformatif, pemahaman terhadap haqîqah mulai dari semua realita yang membawa manusia ke tingkat ma'rifah wajib direalisasikan/ dikontekstualisasikan ke dalam konteks social-masyarakat. Tasawuf transformatif banyak ditemui dalam majlis-majlis tasawuf yang ada di Indonesia, salah satunya
\end{abstract}


adalah di Majlis Maiyahan Mbah Nun (Ainun Nadjib) di Propinsi Jogjakarta dan Majlis Zikir Manakib Syekh Abdul Qodir Al-Jailani KH. Ahmad Muzakki Syah di Kabupaten Jember. Acara-acara majlis tersebut diselingi oleh penanaman nilai-nilai dan pengembangan ajaran-ajaran keislaman dan kebangsaan, sehingga akhirnya acara dalam majlis ini dapat bermanfaat bagi perubahan bagi masyarakat terutama peserta jamaah yang istiqamah mengikuti acara majlis ini. Kedua majlis ini beraliran ablussunnah wal jamaah Nahdlatul Ulama (NU). Sebagaimana diketahui, melalui arahan dan bimbingan $\mathrm{KH}$. Hasyim Asy'ari dan diperkuat lagi oleh $\mathrm{KH}$. Ahmad Siddiq dan KH. Abdurrahman Wahid, NU secara kelembagaan mengakui dan menetapkan nilai-nilai pancasila sebagai dasar final bangsa Indonesia.

Kata kunci: Tasawuf Transformatif, Indonesia

\section{Pendahuluan}

Perkembangan Negara Indonesia dalam konteks kebangsaan dan keberagamaan selalu diguncang oleh arus radikalisme. Arus radikalisme atau terorisme selalu mengatasnamakan agama. Anam menjelaskan:

The reality of religious tolerance in Indonesia has always been rocked by the incipient radicalism that can be found everywhere. Ironically, it is always been related to certain religion. Moreover it is against Pancasila as the philosophy and ideology of the nation, especially when they championed the concept of Islamic caliphate. Pancasila is recognized by all religious people as the foundation of the nation. While the concept of Islamic caliphate is in contrary with Pancasila itself, is only accepted by Muslims minority in Indonesia. Thus, it can be said that the radicalism against Pancasila as the ideology of Indonesia. ${ }^{17}$

Sampai saat ini, arus radikalisme masih terus bermunculan, bahkan ironisnya arus radikalisme sudah menyebar di lembaga pendidikan. ${ }^{18}$ Arus radikalisme tersebut menegaskan posisi manusi sebagai sosok yang individualistic dan eksklusivistik dan sosok yang kurang mengenali eksistensi realita hidupnya. Akibatnya, kehidupan ini

${ }^{17 N u r u l ~ A n a m, ~ I n s t r u c t i o n a l ~ O f ~ C h a r a c t e r ~ E d u c a t i o n ~ I n ~ T h e ~ C o n t e x t ~ O f ~ I r f a n i-A k b l a q i ~ T a s a w n f, ~}$ International Conference on Education 2017: Educational and Innovation in Science in the Digital Era, Graduate School of Universitas Negeri Malang, 668.

18 Berdasarkan hasil survei Kajian Islam Perdamaian (LaKIP) di wilayah Jabodetabek menunjukkan bahwa ada peningkatan kecenderungan radikalisme agama di kalangan siswa yang mencapai 48,9 persen dan guru agama yang mencapai 28,2 persen (Tempo, 29 April 2011). Hasil penelitian Faracha Ciciek di tujuh kota, yaitu: Padang, Jakarta, Pandeglang, Jember, Cianjur, Cilacap, dan Yogyakarta menunjukkan bahwa para guru agama Islam dan siswanya mempunyai sikap intoleransi beragama. 13 persen siswa mendukug aksi radikalisme agama dan 14 persen yang mendukung cara Imam Samudra (Tempo. 6-12 Juni 2011). Sedangkan Forum Kerukunan Umat Beragama Cilacap mengangkat temuan tentang indikasi penggantian Pancasila dengan konsep Khilafah yang menyebar di 14 sekolah di kabupaten tersebut (Tempo, 19 April 2017). 
terjadi suatu polarisan hewaniyah yang menjadi hokum rimba sebagai pedoman merekan. ${ }^{19}$ Berbagai aksi radikalisme dan penyebarannya disebabkan oleh faktor doktrin agama yang ekstrem, sosial, ekonomi, politik dan sebagainya. Aksi radikalisme tersebut sangat tidak relevan dengan pancasila sebagai falsafahdan ideologi Negara dan Bangsa Indonesia, apalagi dalam aksi tersebut mereka memperjuangkan konsep khilafah Islamiyah. Pancasila berisi nilai-nilai yang sangat mengagungkan nilai ketauhidan, himanitas, persatuan dan uhuwah, kebijaksanaan serta keadilan. Pancasila diakui oleh semua umat beragama sebagai dasar negara. Sedangkan konsep khilafah Islamiyah sebagai konsep bernegara yang bertentangan dengan pancasila, karena konsep tersebut hanya diterima oleh kalangan minoritasi umat Islam yang ada di Indonesia. Jadi, aksi tersebut tidak sesuai terhadap nilai-nilai dari pancasila yang merupakanfalsafah dan ideologi Negara dan Bangsa Indonesia.

Dari kenyataan tersebut, terdapat beberapa cara untuk mengatasinya antara lain dengan menggunakan pendekatan tasawuf transformatif. Tasawuf transformatif merupakan upaya untuk pelibatan diri seorang sufi dalam memperbaiki dan merubah kehidupan masyarakat. Tasawuf Transformatif memiliki misi yang sama dengan neo sufisme Nurcholish Madjid dan tasawuf modern Hamka. Tasawuf transformatif tidak menekankan sikap spiritualisme pasif dan isolatif (i'tizaliyah), ${ }^{20}$ tetapi tasawuf dijadikan spiritualisme aktif dan dinamis dengan menjadikan tasawuf sebagai sumber nilai dan semangat untuk menjadikan masyarakat lebih berkarakter, mandiri dan sejahtera.

Di Indonesia, tasawuf transformatif banyak dijadikan sebagai alat dan wadah untuk melakukan perubahan masyarakat yang berpedoman/terpusat pada 5 nilai ddi dalam pancasila. 5 nilai utama itu tidak menjadi perlawanan dengan nilai-nilai Islami, bahkan 5 nilai itu salah satunya bermuara dari nilai-nilai Islami termasuk juga nilainilai tasawuf. Nilai-nilai Pancasila dilihat dari perspektif tasawuf akan semakin memperkuat posisi Pancasila sebagai falsafat dan ideologi Negara dan Bangsa Indonesia. Penghayatan dan pelaksanaan nilai-nilai Pancasila dalam perspektif tasawuf diharapkan akan membentuk karakter pancasilais yang mampu membentuk karakter yang terpuji dalam berkehidupan sosial, berbangsa dan bernegara Indonesia. ${ }^{21}$ Menurut Amsal Bakhtiar ${ }^{22}$ berharap bahwa melalui tasawuf dan kaum sufi, nilai-nilai yang paling utama dan humanitas semakin kuat pada warga Negara Indonesia dengan ajaran atau konsep cinta/mahabbah di dalam dunia sufistik. Di

\footnotetext{
${ }^{19}$ Nurul Anam, Mengurai Benang Kusut Indikasi Kematian Massal Eksistensi Tuhan Di Abad Globalisasi, Ulumuna IAIN Mataran, Volume XIII Nomor 2, Desember 2009, 355.

${ }^{20}$ Usep Taufik Hidayat, Tracking the Roots of Neo-Sufism Muhammad 'Abduh and Muhammad Rashîd Ridhâ in Tafsîr al-Manâr, Jurnal Bimas Islam Vol. 7. No.I 2014, 157-159.

21 Lebih jelasnya, lihatlah buku Amin Khakam el-Chudlrie, Tasawuf Pancasila (Menggali Nilai-Nilai Tasawnf dalam Pancasila), (Jepara: Ar-Raudhoh Press, 2016).

22 Amsal Bakhtiar, Pidato Ilmiah dalam Acara Konferensi Pertama Berskala Internasional tentang Tasawuf atau Mistisisme Islam dengan tema International Conference on Sufism (ICS): Building Love and Peace for Indonesian Society (Rahmatan lil Alamiin). Diselenggarakan oleb Sekolah Tinggi Filsafat Islam (STFI) Sadra, bekerja sama dengan Fakultas Filsafat Universitas Gadjah Mada (UGM) pada tanggal 18 November 2016.
} 
samping itu, ajaran tasawuf relevan dan realistis/kontekstual dalam kehidupan masyarakat yang dinamis dan semangat berbangsan dan bernegara yang berlandaskan pada nilai-nilai luhur Pancasila. Dengan tradisi/ada kesufian, masyarakat dapat melestarikan dan mengembangkan/meningkatkan nilai-nilai dan materi tasawuf agar kemudian ditanamkan ke dalam jiwa masyarakat bangsa Indonesia terutama anakanak didik untuk membentuk dan mengembang karakter pancasilais.

\section{Tinjauan Tentang Tasawuf}

Secara etimologis dan terminologis, istilah tasawuf memiliki berbagai definisi. Salah satunya yaitu kata 'tasawuf berawal dari istilah baha arab 'shafa' yang bermakna suci, yaitu ibadah atau sembahya hamba penuh ke-sucian hati dan supaya jiwa itu bersih karena Sang Tuhan YME. ${ }^{23}$ Sedangkan secara terminologi, Abudin Nata ${ }^{24}$ memberikan berbagai diskripsi tentang istilah tasawuf dari perspektif sebagai: a) hamba yang terbatas, istilah tasawuf dipahami sebagai usaha menjernihkan jiwa/diri dengan cara menghindarkan diri dari urusan ke-dunia-wian dan memusatkan konsentrasi hamba hanya Tuhan YME.; b) hamba yang wajib bersungguhsungguh/berjuang, istilah tasawuf diartikan upaya 'mempercantik' jiwa/diri dengan perilaku atauk akhlak yang berpusat atau berpedoman dari ajaran agama Islam untuk selalu dengan Sang Pencipta; dan c) hamba yang bertuhan, istiilah tasawuf dipahami sebagai kesadaran ketuhanan (kefitrahan)yang mampu membimbing jiwa supaya mengarah ke aktifitas-aktfitas yang 'mengintimkan' hubungan hamba dengan Sang Pencipta.

Di dalam konteks tasawuf, terdapat beberapa nilai yang menjadi dasar dalam pelaksanaan tasawuf. Muhyidin ${ }^{25}$ menyebutkan, nilai-nilai tasawuf, yaitu: 1) tauhid, 2) fikih, 3) akhlak, 4) keikhlasan, 5) kesucian, dan 6) KitabAl-Qur'an dan KitabasSunnah. Nilai tauhid merupakan sesuatu yang menjadi sumber dari nilai-nilai lain. Imam Ghazali berpendapat, bahwa tauhid terbagi menjadi tiga dan di dalamnya terdapat nilai-nilai yang harus diyakini dan dilaksanakan oleh hamba-Nya, yaitu: nilai tauhid rububiyyah,tauhid ulubiyahdan tauhidasma wa sifat. Dengan demikian, nilai-nilai tasawuf dan tauhid saling berkaitan dan tidak bisa dipisahkan. Penelitian Said Aqiel Siradj $^{26}$ yang berjudul, Tawhid in The Perspective of Tasawnf, menyebutkan bahwa artikulasi konsep sufi dari tauhid, kesatuan Allah. Tauhid selalu menjadi masalah yang menarik untuk mengatasi dalam lokasi dari tasawuf mengingat bahwa itu adalah gagasan yang telah memicu kontroversi selama berabad-abad. Para sufi sering dituduh mengkhianati Islam dengan menghadirkan versi terdistorsi tauhid. Tulisan ini

23 Jamil, Cakrawala Tasawuf, Sejarah, Pemikiran dan Kontektualitas (Jakarta : Gaung Persada Press, 2007), 2 .

${ }^{24}$ Abuddin Nata, Akblak Tasawuf(Jakarta : PT. Raja Grafindo Persada, 2000), 180.

25 Muhammad Muhyidin, Kasidah-kasidah Cinta: Novel Spiritual Keajaiban Cinta. (Yogyakarta: Diva Prees, 2007), 393.

26 Said Aqiel Siradj, Tawhid in The Perspective of Tasawnf, Jurnal Islamica, Vol. 5, No. 1, September 2010, 152-160. 
akan menetralkan tuduhan ini dan berpendapat bahwa konsep sufistik dari tauhid adalah kategoris Islam, Al-Qur'an dan kenabian.

Untuk menginternalisasikan nilai-nilai tersebut, maka langkah yang harus dilakukan adalah menerapkan metode riyadhah. Metode ini biasanya berbentuk dzikir. Hasil penelitian Wardi ${ }^{27}$ menjelaskan bahwa metode drikr dalam tarekat Naqsyabandiyah menunjukkan bahwa taubat sebagai sarana untuk mensucikan diri (tazkiyat al-nafs). Proses tarkiyat al-nafs terlebih dahulu dimulai dengan membersihkan hati (al-takhalli) dari sifat-sifat yang tidak terpuji/tercela, kemudian tahalli, yaitu dengan pengisian hati dari sifat-sifat yang tidak tercela/terpuji. Metode dziker

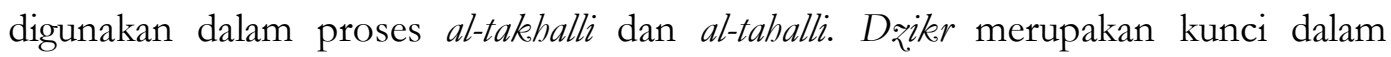
menempati posisi yang sangat penting dalam tradisi tarekat. Tarekat Naqsyabandiyah mengenal dua macam dzikr yang dilakukan dengan cara samar dalam hati (khafi) dan jelas dengan lisan (jahr), yaitu dziker-ism al-Dzat(menyebut nama Sang Pencipta) dan dziker nafi itsbat(mengucapkan lafadz 'La ilaha illa Allab).

Apabila metode riyadhah ini dilaksanakan dengan baik dan istiqamah, maka orang tersebut akan mencapai tingkat yang tertinggi dalam dunia tasawuf. Di konteks tasawuf, terdapat berbagai level tingkatan untuk memperoleh tingkat sufi tertinggi, yaitu syari'at, tarekat, hakikat dan ma'rifat. Pertama, syariat. Syariat tidak saja berkaitan dengan rukun Islamyang nomer dua tentang solat), ketiga tentang zakat, keempat tentang puasa dan kelima tentang (haji, namun juga berkaitan dengan aturan hidup yang membimbing dan mengarahkan manusia mencapai realitas yang substantif. Kedua, tarekat. Istilah ini diapahami sebagai upaya menuntun pada usaha penjernihan jiwa. Menurut Schimmel, ${ }^{28}$ tarekat merupakan langkah spiritual bagi penempuh jalan ruhani (salik) dalam mewujudkan tingkat pemantapan tauhid (márifatullah). Ketiga, hakikat. Sebagian tokoh menyamakan istilah hakikat dengan Lubb. Artinya adalah dalam atau sari pati, inti atau esensi. Mulyadhi Kartanegara ${ }^{29}$ menjelaskan, hakikat merupakan dari perspektif kebanyakan tokoh sufi yang menyakini mereka/hamba sebagai 'abl-haqiqah' yaitu sebagai kaca/pencerminan keinginan kuat mereka pada realita kebenaran/hakikat yang mutlak (kebenaran yang absolute dan esensial). Di antara sufi yang mencontohkan dan menerapkan yaitu al-Hallaj (w. 922). Dia mendiskripsikan dirinya dengan istilah Aku adalah Tuhan (ana al-Haqq). Keempat, makrifat. Istilah makrifat adalah usaha spritual untuk menemukan pengenalan, pengetahuan atau pemahaman sejati dan membuka mata batin hamba. Makrifat, makhafah dan mahabbah dipahami sebagai bagian dari tritunggal. Ketiga unsur ini merupakan diskripsi perilaku hamba yang menempuh thariqat. ${ }^{30}$

27 Moh. Wardi, Internalisasi Nilai-Nilai Sufisme dan Tarekat dalam Pendidikan Islam, Makalah Hasil Penelitian Program Pascasarjana Program Doktor UIN Sunan Ampel Surabaya, Tt., 8.

28 Annemarie Schimmel, Mystical Dimensions Of Islam, (USA: The University of North Carolina Press, 1975), 98.

${ }^{29}$ Mulyadhi Kartanegara. Menyelami Lubuk Tasawuf. (Jakarta: Penerbit Erlangga, 2006), 6

30 Tim Penyusun, Ensiklopedi Tasawuf jilid II. (Jakarta: UIN Syarif Hidayatullah, 2008), 798. 


\section{Pembagian Tasawuf}

Sebagaimana pendapat Ismail Hasan, ${ }^{31}$ ada tiga pembagian Tasawuf yang terkenal yaitu, Tasawuf falsafi, tasawuf akhlaqi dan tasawuf syi'i. Untuk pembahasan lebih mendalam, maka peneliti akan membahas macam-macam tasawuf sebagai berikut: pertama, Falsafi. tasawuf ini merupakan tasawuf yang dipusatkan kepada konvergensi konsep-konsep filsafat dan tasawuf atau disebut dengan metafisika mistik. Kedua, Akhlaqi. Tasawuf ini merupakan bagian tasawuf yang mengkhususkan pada konsep-konsep tingkah laku, akhlak atau perbuatan budi pekerti atau perbaikan ahlak. Untuk memperbaiki akhlak ada beberapa tahapan yang harus dilalui yakni: 1) takhalli, dimaknai sebagai upaya pengosongan diri dari perilaku yang sangat tergantung pada kenikmatan di dunia; ${ }^{32}$ 2) tahalli. Tahapan ini dimaksudkan dengan proses pengisias jiwa dengan sifat-sifat baik dengan penuk ketaatan baik rohani maupun jasmani; ${ }^{33}$ dan 3) tajalli. Tahapan ini diartikan sebagai penyatuan dan perwujudan diri Sang Pencipta yang mutlah dan absolut dalam lingkup alam sangat terbatas. $^{34}$

Bagi Ibn Arabi, tajalli tidak hanya perjujudan/penampakan Sang Pencipta bagi hamba yang mengalami keterlihatan pintu dari mata batin hamba (kasyf), akan tetapi tidak hanya itu. Perspekti Ibn Arab, pengetahuan/ilmu kasyf memberi pengetahuan bahwa alam ini merupan tajali Sang Pencipta dalam wujud atau bentuk yang variatif, relevan dengan konsep-konsep tetap (tentang alam) dalam ilmu Tuhan. Bentuk ini dengan bentuk yang lain akan berbeda, karena bentuk suatu tajalli tidak akan/pernah terulang, dan wujud itu akan selalu terus-menerus tanpa ada akhirnya. ${ }^{35}$

\section{Tasawuf Transformatif di Indonesia}

Islam mempunyai visi rahmatan lil'alamin, sehingga jika ada persoalan umat, maka Islam harus melakukan upaya transformatif untuk mengatasi persoalan umat. Islam Transformatif merupakan upaya agama untuk menganalisis dan memberikan alternatif solusi terhadap segala bentuk dehumanisasi sosial. Islam adalah agama yang hakikatnya bukanlah milik perseorangan atau kelompok. Islam diturunkan sebagai petunjuk dan rahmat untuk membebaskan manusia dari semua bentuk perbudakan atau penghambaan yang melawan nilai-nilai teologis dan nilai-nilai dasar kemanusiaan. ${ }^{36}$ Islam tidak bisa diposisikan sebagai agama yang statis untuk untuk dirinya sendiri, tetapi harus ditransformasikan dan ditafsirkan oleh umat manusia. Transformasi inilah yang bisa disebut sebagai bentuk riil dari gerakan sosial baru. ${ }^{37}$

\footnotetext{
${ }^{31}$ Ismail Hasan, Tasawuf: Jalan Rumpil Menuju Tuhan, Jurnal An-Nuha STAI Madiun, Vol. 1, No. 1, Juli 2014, 52-61..

32 Usman Said, dkk, Pengantar Ilmu Tasawuf (Medan: Naspar Djaja, 1981 ), 99.

33 Asmaran, Pengantar Studi Tasawuf, 69

34 Ibid. 70.

35 Ibid, 59.

36 Moeslim Abdurrahman, Islam Transformatif, (Jakarta: Pustaka Firdaus, 1997), 66

37 Zuly Qodir, Islam Liberal: Paradigma Baru Wacana dan Aksi Islam Indonesia, (Yogyakarta: Pustaka Pelajar, 2003), 23.
} 
Maka dari itu, Islam merupakan agama yang akan memberikan kedamaian dan kesejahteraan bagi seluruh umat yang ada di dunia ini.

Di dalam Islam terdapat unsur tasawuf yang menjadi bagian yang sangat signifikan bagi keberadaan Islam transformatif. Dari Islam tranformatif ini muncul istilah tasawuf tranformatif. Tasawuf transformatif ini pernah ditawarkan oleh Muhammad Zuhri. Ide ini adalah solusi aplikatif atas masalah yang menimpa manusia di abad ini. Kondisi manusia/masyarakat di abad ini yang mengalami masalah multidimensional. Tasawuf ditampilkan Zuhri sebagai keseimbangan antara rasiionalitas dan spiritual, dengan selalu melaksanakan pemahaman makna lagi terhadap dimensi inner journey manusia, yang bias mungkin hamba menjadi zubd dan punya efek sosial. ${ }^{38}$

Tasawuf transformatif bersumber pada tauhid dan syari'at, sehingga dalam prakteknya tidak menyimpang dari akidah dan syariat. Sebagaimana menurut Hamka, hakikat konsep tasawuf harus berada dalam lingkup pondasi akidah yang bersih dari pengamalan kemusyrikan. ${ }^{39}$ Tasawuf merupakan suatu proses menuju makrifatullah dengan melalui tiga proses yaitu: 1) taholli, yaitu suatu proses mengosongkan diri dari ahlak/karakter tidak terpuji, 2) tahalli, yaitu suatu proses meliputi atau mengisi diri dengan ahlak/karakter Islami dan 3) tajalli, yaitu suatu pencapaian sufistik yang menempatkan Allah selalu hadir dalam setiap nafas dan perbuatannya. ${ }^{40}$ Dengan demikian, tasawuf sebagai upaya jalan menuju makrifatullah, sehingga masyarakat memiliki karakter Islami dan jauh dari perbuatan tidak terpuji.

Di samping itu, dalam konteks ke-Indonesiaan, tasawuf banyak dijadikan sebagai alat dan wadah untuk menjadikan masyarakat berkarakter pancasilais. Karakter pancasilais ini tidak bertentangan dengan karakter Islami. Nilai-nilai Pancasila dilihat dari perspektif tasawuf akan semakin dapat memperkuat posisi Pancasila. Penghayatan dan pelaksanaan nilai-nilai Pancasila dalam perspektif tasawuf, diharapkan akan membentuk karakter pancasilasi yang mampu membentuk karakter yang terpuji dalam berkehidupan sosial, berbangsa dan bernegara Indonesia. ${ }^{41}$ Menurut Amsal Bakhtiar ${ }^{42}$ berharap bahwa melalui tasawuf dan kaum sufi, nilai-nilai keutamaan dan kemanusiaan kian kokoh di masyarakat dengan ajaran cinta sufistik. Ajaran tasawuf juga sangat kontekstual dalam dinamika dan semangat bernegara yang berlandaskan Pancasila. Dengan tradisi sufi, masyarakat dapat mengembangkan nilai-nilai dan muatan tasawuf agar kemudian ditanamkan ke

\footnotetext{
${ }^{38}$ Muhammad Zuhri, Mencari Nama Allah yang Keseratus (Jakarta: Serambi, 2007), 19-21.

${ }^{39}$ Hamka, Tasawuf, Perkembangan dan Pemurniannya, (Jakarta: PT. Pustaka Panjimas, 1984), 59.

${ }^{40}$ Hamka, Renungan Tasawuf, (Jakarta: Pustaka Panjimas, 1995), Cet. II, 21-22

${ }^{41}$ Lebih jelasnya, lihatlah buku Amin Khakam el-Chudlrie, Tasawnf Pancasila (Menggali Nilai-Nilai Tasawnf dalam Pancasila), (Jepara: Ar-Raudhoh Press, 2016).

42 Amsal Bakhtia, Pidato Ilmiah dalam Acara Konferensi Pertama Berskala Internasional tentang Tasawuf atau Mistisisme Islam dengan tema International Conference on Sufism (ICS): Building Love and Peace for Indonesian Society (Rahmatan lil Alamiin). Diselenggarakan oleh Sekolah Tinggi Filsafat Islam (STFI) Sadra, bekerja sama dengan Fakultas Filsafat Universitas Gadjah Mada (UGM) pada tanggal 18 November 2016.
} 
dalam jiwa masyarakat bangsa Indonesia terutama anak-anak didik untuk membentuk karakter-karakter pancasilais bangsa.

Terdapat beberapa tokoh atau ulama' sufistik yang memiliki karakter pancasilais karena begitu kuat memegang Pancasila sebagai dasar pedoman hidup dan sumber nilai seperti di antaranya KH. Hasyim Asy'ari, KH. Ahmad Siddiq, KH. Abdurrahman Wahid (Gus Dur) dan sebagainya. Dari tokoh-tokoh inilah, organisasi Nahdlatul Ulama menjadikan dan memperkuat pancasila sebagai dasar final bangsa Indonesia. Keterlibatan para tokoh sufi tidak terlepas dari sejarah Bangsa Indonesia. Amsal Bakhtiar menjelaskan, sejak awal kali jejak agama ini membekas di tanah air, Islam sudah dikenalkan dengan lapisan-lapisan ajaran tasawuf oleh ulama-ulama yang membawa semangat sufistik. Seiring dengan kontribusi tradisi lain, tasawuf melengkapi khazanah eksoteris Islam dalam membangun dan mengembangkan peradaban dan kebudayaan Nusantara. Sejarah perjuangan kemerdekaan bangsa kita juga dibanggakan dengan keterlibatan langsung para pahlawan yang menyimpan kecenderungan tasawuf. Di tanah air, tasawuf tidak hanya dijumpai di ruang-ruang privat dan kelas-kelas eksklusif, tetapi juga kontribusinya mengalir dalam ruang publik dan interaksi sosial. ${ }^{43}$ Dengan demikian, gerakan tasawuf di Indonesia merupakan salah satu gerakan untuk mengamalkan nilai-nilai pancasila, karena nilai-nilai pancasila tidak bertentangan dengan nilai-nilai Islami dan bahkan nilai-nilai pancasila diambil dari "sari pati" nilai-nilai Islam.

Terdapat banyak penelitian yang memperkuat diskripsi di atas ini salah satunya penelitian Sulaiman. Dalam penelitiannya yang bejudul, "Membaca Pancasila: Perspektif Kearifan Sufi Jalall Al-Dinn Rummi”, menyebutkan bahwa Nilai-nilai universal Islam termasuk juga nilai-nilai sufistik Islami secara eksplisit menjiwai muatan Pancasila yang berprinsip ketuhanan, kemanusiaan, persatuan, permusyawaratan, dan keadilan. Nilai-nilai sufistik perspektif kearifan (wisdom) sufi agung Jalal al-Din Rumi (1207-1273) terutama sila Ketuhanan Yang Maha Esa memiliki relevansi yang sangat kuat dengan nilai-nilai pancasila. Oleh karena itu, mengamalkan tasawuf berarti berupaya untuk membentuk dan mengaplikasikan nilainilai karakter pancasila dalam bernegara dan berbangsa Indonesia. Selain itu, dalam penelitian Khafid Ja'far yang berjudul, "Pancasila dalam Perspektif Tasawuf", dijelaskan bahwa tasawuf secara umum ialah pembersihan/ penyucian hati agar terjalin kedekatan hubungan antara manusia dengan Allah. Di dalam tasawuf, terdapat beberapa nilai yang memiliki kesamaan dengan nilai-nilai pancasila. Di indonesia, pelaksanaan nilai-nilai tasawuf berarti melaksanakan nilai-nilai Pancasila terutama pada sila pertama. Pancasila sesuai dengan sila pertamanya maka dalam pengamalan Pancasila haruslah berdasarkan pengamalan terhadap ajaran agama, artinya pengamalan terhadap ajaran Pancasila haruslah sesuai dengan ajaran agama yang dianut oleh rakyat Indonesia. Pancasila secara keseluruhan merupakan sebuah

43 Ibid. 
jalan terhadap kebaikan moral/akhlak, kebaikan bagi kebersihan/kesucian jiwa dalam menjalani kehidupan bagi bangsa Indonesia, demi mewujudkan cita-cita bersama, diatas perbedaan yang ada, sehingga Pancasila dengan demikian memiliki kesesuaian terhadap tasawuf akhlaki yaitu tasawuf yang memiliki orientasi atau kecenderungan pada moral keagamaan. Maka dari itu, pengamalan tasawuf berarti sebagai upaya untuk membentuk karakter pancasilais.

Gerakan-gerakan tasawuf di atas banyak ditemui dalam majlis-majlis tasawuf yang ada di Indonesia, salah satunya adalah di Majlis Maiyah Ainun Nadjib Yogyakarta dan Majlis Dzikir Manaqib Syech Abdul Qodir Jailani K. Muzakki Syah Jember. Acara-acara majlis tersebut diselingi oleh penanaman nilai-nilai dan pengembangan ajaran-ajaran keislaman dan kebangsaan, sehingga akhirnya acara dalam majlis ini dapat bermanfaat bagi perubahan bagi masyarakat terutama peserta jamaah yang istiqamah mengikuti acara majlis ini. Kedua majlis ini beraliran ablussunnah wal jamaah Nahdlatul Ulama (NU). Sebagaimana diketahui, melalui arahan dan bimbingan KH. Hasyim Asy'ari dan diperkuat lagi oleh KH. Ahmad Siddiq dan KH. Abdurrahman Wahid, NU secara kelembagaan mengakui dan menetapkan nilainilai pancasila sebagai dasar final bangsa Indonesia. ${ }^{44}$

Kedua majlis tersebut menerapkan dan mengembangkan nilai-nilai pancasila. Di majlis Maiyah, Cak atau Mbah Nun Nun menjadi pemimpin majlis sufistik. Selain seorang ilmuwan dan budayawan, Cak Nun juga seorang penulis sastra sufistik. Cak Nun merupakan salah satu sastrawan Indonesia yang telah dan sedang menghasilkan karya sastra sufistik dan atau sastra profetik. Jamaah Maiyah adalah salah satu gerakan sufi yang memiliki persamaan dengan jamaah malamatiyah. Jamaah ini menjadi wadah untuk bernaung masyarakat dalam melawan berbagai keserakahan, keberpihakan pada pihak tertentu maupun bersika represif dan otoriter yang digunakan oleh oknum pemerintahan atau pengambil kebijakan. Jamaah ini juga cenderung melaksanakan dan membiasakan perasaan kebahagiaan dan sikap memahami keadaan yang tidak adil dan kesengsaraan yang dihadapinya. Forumforum Maiyah Mbah Nun telah memposisikan sebagai wadah atau danau yang akan menyerap segala banjir yang diliputi kemungkaran dan dendam masyarakat. Forum ini berfungsi sebagai 'gegana' yang akan menjinakkan segala 'bom' yang sewaktuwaktu akan meletus dan melukai, karena diskriminasi yang massif dalam masyarakat. Forum ini berfungsi sebagai media ampuh dalam mewujudkan perdamaian apabila konflik bergejolak di masyarakat. Bahkan dari itu, forum ini juga berfungsi sebagai 'lembaga pendidikan' dalam realita hidup masyarakat sehingga akhirnya akan menyebarkan pendidikan hidup yang penuh dengan arif dan bijaksana.

Sedangkan majlis terakhir yaitu majlis Zikir Manakib Syekh Abdul Qodir Jailani Jember dipimpin oleh KH. Muzaki Syah. Gerakan dzikir tersebut berkembang pesat. Tidak hanya di kawasan Jember dan sekitarnya, namun sudah merambah keseluruh

${ }_{44}$ Abdul Muchit Muzadi, NU dalam Perspektif Sejarah dan Ajaran: Refleksi 65 Tabun Ikut NU. (Surabaya: Khalista, 2006), 75-76. 
penjuru dunia. Sebut saja Malaysia, Brunei Darussalam, India, Australia, Mesir dan Arab Saudi. Acara Dzikir Manaqib ini dilaksanakan pada hari malam jumat terutama malam jumat legi. Para jamaahnya berkumpul dan bersatu dalam satu tempat. Para jamaah berasal dari berbagai latar belakang SARA (SARA). Mereka semua diperlakukan sama dan adil. Mereka menghadiri acara tersebut untuk mendekatkan diri pada Allah dan Nabi Muhammad, memahami ajaran Islam ala NU atau Ahlussunnah wal Jamaah, selalu menjaga NKRI dan berpegang teguh pada pancasila. Mereka menyanyikan lagu Indonesia Raya, berdzikir, bersolawat dan berdoa bersamasama untuk kepentingan individu, masyarakat, bangsa dan agama. Para jamaah juga diajarkan untuk bersikap simpati dan empati dengan cara bersodaqah harta dan do'a kepada umat yang ada di dunia ini terutama di Negara Indonesia. ${ }^{45}$

Terdapat banyak tokoh yang telah mengakui peran dzikir manaqib ini. Salah satunya adalah Said Aqil Siradj (Ketua Umum PBNU) yang menjelaskan, Zikir yang dilestarikan, ditingkatkan dibumikan dalam kehidupan masyarakat, di samping berisi semangat/spirit yang membebaskan masyarakat dari semua wujud ketidak-adilan, keterbawahan dan dis-kriminasi. Zikir ini akan antibodi/obat yang membuat manusia memiliki kekuata, yang bisa menghadapi beraneka ragam ketidak-mudahan kehidupan yang dihadapinya. ${ }^{46}$ Sedangkan Mantan Menteri Tenaga Kerja, Drs. H. Muhaimin Iskandar, M.Si ${ }^{47}$ memiliki pandangan terhadap acara dzikir manaqib tersebut. Dia menerangkan, dia menemukan antara lain dua fakta, yaitu zikir ini sangat baik dan efektif untuk menghilangkan masalah masyarakat dan bangsa Indonesia serta dia sangat sadar dengan sepenuh hati bahwa manusia tidak memiliki power apapun tanpa ada faktor karomah para wali. Dia menambahkan bahwa jika seluruh anak bangsa mengamalkan secara istiqomah dzikir manaqib, maka seluruh pemasalah multi sektor/dimensi yang dihadapi bangsa akan cepat selesai.

\section{Penutup}

Di dalam Islam terdapat unsur tasawuf yang menjadi bagian yang sangat signifikan bagi keberadaan Islam transformatif. Dari Islam tranformatif ini muncul istilah tasawuf tranformatif. Tasawuf transformatif ini pernah ditawarkan oleh Muhammad Zuhri. Ide ini adalah solusi aplikatif atas masalah yang menimpa manusia di abad ini. Kondisi manusia/masyarakat di abad ini yang mengalami masalah multidimensional. Tasawuf ditampilkan Zuhri sebagai keseimbangan antara rasiionalitas dan spiritual, dengan selalu melaksanakan pemahaman makna lagi terhadap dimensi inner journey manusia, yang bias mungkin hamba menjadi zubd dan punya efek sosial.

Proses tasawuf transformatif bermula dan berpusa pada pemahaman atau pengetahuan tentang Sang Pencipta (ma'rifah) serta perspektif konsep tauhid. Dalam konteks tasawuf tranformatif, pemahaman terhadap haqîah mulai dari semua realita

45 Observasi dan Dokumentasi, sejak mengikuti Dzikir Manaqib pada tahun 2012.

46 Moch. Chotib, Wisata Religi di Kabupaten Jember. Jurnal Fenomena Pusat Penelitian dan Penerbitan Lembaga Penelitian dan Pengabdian Kepada Masyarakan (LP2M) IAIN Jember, Vol. 14, Nomor 2 Oktober 2015, 419-420.

47 Ibid., 419. 
yang membawa manusia ke tingkat ma'rifah wajib direalisasikan/ dikontekstualisasikan ke dalam konteks social-masyarakat.

Gerakan-gerakan tasawuf di atas banyak ditemui dalam majlis-majlis tasawuf yang ada di Indonesia, salah satunya adalah di Majlis Maiyahan Mbah Nun (Ainun Nadjib) Jogjakarta (Yogyakarta) dan Zikir Manakib Syekh Abdul Qodir Jailani KH. Ahmad Muzakki Syah di Kabupaten Jember. Kedua majlis tersebut menerapkan dan mengembangkan nilai-nilai pancasila. Di majlis Maiyah, Cak atau Mbah Nun Nun menjadi pemimpin majlis sufistik. Selain seorang ilmuwan dan budayawan, Cak Nun juga seorang penulis sastra sufistik. Cak Nun merupakan salah satu sastrawan Indonesia yang telah dan sedang menghasilkan karya sastra sufistik dan atau sastra profetik. Jamaah Maiyah adalah salah satu gerakan sufi yang memiliki persamaan dengan jamaah malamatiyah. Jamaah ini menjadi wadah untuk bernaung masyarakat dalam melawan berbagai keserakahan, keberpihakan pada pihak tertentu maupun bersika represif dan otoriter yang digunakan oleh oknum pemerintahan atau pengambil kebijakan. Jamaah ini juga cenderung melaksanakan dan membiasakan perasaan kebahagiaan dan sikap memahami keadaan yang tidak adil dan kesengsaraan yang dihadapinya. Forum-forum Maiyah Mbah Nun telah memposisikan sebagai wadah atau danau yang akan menyerap segala banjir yang diliputi kemungkaran dan dendam masyarakat. Forum ini berfungsi sebagai 'gegana' yang akan menjinakkan segala 'bom' yang sewaktu-waktu akan meletus dan melukai, karena diskriminasi yang massif dalam masyarakat. Forum ini berfungsi sebagai media ampuh dalam mewujudkan perdamaian apabila konflik bergejolak di masyarakat. Bahkan dari itu, forum ini juga berfungsi sebagai 'lembaga pendidikan' dalam realita hidup masyarakat sehingga akhirnya akan menyebarkan pendidikan hidup yang penuh dengan arif dan bijaksana.

\section{Daftar Pustaka}

Abdurrahman, Moeslim. Islam Transformatif, Jakarta: Pustaka Firdaus, 1997.

Ansari, Muhammad Abdul Haq. Sufism and Shari'ah, A study of syakh Ahmad Sirbindi's Effort to reform Sufism, Malaysia: The Islamic Foundation, 1990.

Anwar, Wan. Kuntowijoyo: Karya dan Dunianya. Jakarta: Grasindo, 2007.

Asmaran, Pengantar Studi Tasawnf, Jakarta: Raja Grafindo Persada, 1996.

Bakhtiar, Amsal. Pidato Ilmiah dalam Acara Konferensi Pertama Berskala Internasional tentang Tasawuf atau Mistisisme Islam dengan tema International Conference on Sufism (ICS): Building Love and Peace for Indonesian Society (Rahmatan lil Alamiin). Diselenggarakan oleh Sekolah Tinggi Filsafat Islam (STFI) Sadra, bekerja sama dengan Fakultas Filsafat Universitas Gadjah Mada (UGM) pada tanggal 18 November 2016.

El-Chudlrie, Amin Khakam. Tasawuf Pancasila Menggali Nilai-Nilai Tasawuf dalam Pancasila), Jepara: Ar-Raudhoh Press, 2016.

Hamka, Tasawnf, Perkembangan dan Pemurniannya, Jakarta: PT. Pustaka Panjimas, 1984.

-------, Renungan Tasawuf, Jakarta: Pustaka Panjimas, 1995. 
Hasan, Ismail. Tasawuf: Jalan Rumpil Menuju Tuban, Jurnal An-Nuha STAI Madiun, Vol. 1, No. 1, Juli 2014

Hidayat, Usep Taufik. Tracking the Roots of Neo-Sufism Mubammad 'Abduh and Muhammad Rashîd Ridhâ in Tafsîr al-Manâr, Jurnal Bimas Islam Vol. 7. No.I 2014.

Jamil, Cakrawala Tasawnf, Sejarah, Pemikiran dan Kontektualitas. Jakarta : Gaung Persada Press, 2007.

Kartanegara, Mulyadhi. Menyelami Lubuk Tasawuf. Jakarta: Penerbit Erlangga, 2006.

Majalah Dzikir Pencerah Hati, 2007.

Maksum, Ali. Tasawnf sebagai Pembebasan Manusia Modern, Surabaya: PSAPM, 2003.

Muhyidin, Muhammad. Kasidah-kasidah Cinta: Novel Spiritual Keajaiban Cinta. Yogyakarta: Diva Prees, 2007.

Muzadi, Abdul Muchit. NU dalam Perspektif Sejarah dan Ajaran: Refleksi 65 Tahun Ikut NU. Surabaya: Khalista, 2006.

Nata, Abuddin. Akblak Tasawnf. Jakarta : PT. Raja Grafindo Persada, 2003.

Qodir, Zuly. Islam Liberal: Paradigma Baru Wacana dan Aksi Islam Indonesia, Yogyakarta: 2003.

Said, Usman dkk, Pengantar Ilmu Tasawuf, Medan: Naspar Djaja, 1981.

Schimmel, Annemarie. Mystical Dimensions Of Islam, USA: The University of North Carolina Press, 1975.

Siradj, Said Aqiel. Tawhid in The Perspective of Tasawnf, Jurnal Islamica, Vol. 5, No. 1, September 2010.

Sugiyono. Metode Penelitian Kuantitatif, Kualitatif, dan R\&D, Cet. 21. Bandung: Alfabeta, 2014.

Tim Penyusun, Ensiklopedi Tasawnf jilid II. Jakarta: UIN Syarif Hidayatullah, 2008.

Wahab, Abdul. Menulis Karya Ilmiah. Surabaya: Airlangga University Press, 1999.

Wardi, Moh. Internalisasi Nilai-Nilai Sufisme dan Tarekat dalam Pendidikan Islam, Makalah Hasil Penelitian Program Pascasarjana Program Doktor UIN Sunan Ampel Surabaya, Tt.

Yulianto, Rahmad. Tasawuf Transformatif sebagai Solusi Problematika Manusia Modern dalam Perspektif Tasawuf Muhammad Zubri, Teosofi: Jurnal Tasawuf dan Pemikiran Islam, Volume 4, Nomor 1, Juni 2014.

Zaini, Nur. 2011. Pendidikan Karakter dalam Perspektif Islam, Makalah disajikan dalam seminar kelas, pada mata kuliah Trend and Issue Contemporary of Islamic Studies, yang diampu oleh Prof. Dr. Toha Hamim, Program Pascasarjana (S-3) IAIN Sunan Ampel Surabaya, tanggal 7 Nopember 2011.

Zuhri, Muhammad. Hidup Lebih Bermakna, Jakarta: Serambi, 2007. Mencari Nama Allah yang Keseratus. Jakarta: Serambi, 2007. 